Vol. : : 2 (1), 2020, 112-132

P-ISSN : 2686-1607

E-ISSN : 2686-4819

\title{
IMPLEMENTASI WAKAF UANG PADA ISLAMIC MICROFINANCE INSTITUTION DI ERA SOCIETY 5.0
}

\author{
Eny Latifah, Mia Lailatul Hidayah \\ Institut Agama Islam Tarbiatut Tholabah Lamongan \\ email: eni.lathifah@gmail.com, mialailatulhidayah10@gmail.com
}

\begin{abstract}
The purpose of this reseach is to find out the implementation in channeling the endoWment of money to the authorities and the motives of customers in the endowment of money in The Islamic Microfinance Institutions called KSPPS Mandiri Sejahtera in Era Society 5.0. The resuts of the reseach are the process of channeling the results of Waqf money starting from Waqif handing over money to kspps Mandiri Sejahtera through the purchase of Waqf voucher money . then managed endowment fund and distributed funds to people in need. Motives of customers at KSPPS BMT Mandiri Sejahtera have a motive, Which is forced by the relevant regulations, such as compliance with payment administration, staff who work there every month are deducted from their waqf money. The next motive in managing money Waqf money voucher seems to force Waqif because most do not have the urge of oneself to endowment but compulsion and even the obligation to pay endowment for money to get what customers want, such as internship, field work practices, and reseach.
\end{abstract}

Keywords: Waqf Money, Islamic Microfinance Institution, Era Society 5.0

Abstrak: Tujuan penelitian adalah ingin mengetahui impelementasi
dalam menyalurkan wakaf uang kepada pihak yang berwenang, dan motif
nasabah dalam wakaf uang yang ada di Islamic Microfinance Institution
yang bernama KSPPS Mandiri Sejahtera di Era Society 5.0. Hasil penelitian
adalah Proses penyaluran hasil wakaf uang dimulai dari waqif
menyerahkan uang kepada KSPPS BMT Mandiri Sejahtera melalui
pembelian voucher wakaf uang Kemudian di kelola dana wakaf uangnya
dan salurkan kepada orang-orang yang membutuhkan. Motif nasabah di
KSPPS BMT Mandiri Sejahtera memiliki motif, yaitu motif yang terpaksa 
dengan peraturan yang terikat seperti pemenuhan administrasi pembiayaan, staf yang bekerja disana setiap bulan gajinya akan dipotong untuk wakaf, motif selanjutnya dalam melakukan pengelolaan voucher wakaf ini terkesan memaksa waqif karena kebanyakan tanpa dorongan dari diri sendiri untuk wakaf melainkan paksaan bahkan kewajiban untuk membayar wakaf uang demi mendapatkan apa yang diinginkan nasabah, seperti magang, Praktek Kerja Lapnagan, dan Penelitian.

Kata Kunci: Wakaf Uang, Islamic Microfinance Institution, Era Society 5.0

\section{PENDAHULUAN}

Koperasi syariah yang masuk kategori Islamic Microfinance Institutions di Indonesia semakin tahun semakin bertambah jumlahnya, koperasi yang tercatat di wilayah Jawa Timur tahun 2009 sebanak 19.396 buah, tahun 2013 mulai melonjak jumlahnya menjadi 30.741. dan di tahun 2018 tercatat jumlah koperasi yang ada di Wilayah Jawa Timur sebanyak 33.871 (Data menurut Data dari Dinas Koperasi Jawa Timur di acara Hari Pers Nasional 2019 di Surabaya).

Perkembangan koperasi tersebut haruslah di imbangi dengan Sumber Daya Manusia yang nantinya mampu mengemban amanah dari masyarakat yang semakin lama memilih koperasi sebagai lembaga keuangan pendamping dalam memenuhi kebutuhan dan pengadaan dana tambahan dengan persyaratan yang tidak rumit bila dibandingkan dengan perbankan.

Kepercayaan dan tanggungjawab tidaklah mudah untuk dijalankan, haruslah memiliki jiwa tulus dan ikhlas dalam menjalankan segala amanah yang di bebankan kepadanya. Perlu adanya control keperilakuan yang berasal dari dalam diri sendiri untuk bisa menyajiakan laporan atas apa yang telah dijalankan. 
Dan banyak juga masyarakat yang sanki atas lembaga keuangan yang ada di sekitar wilayah Lamongan khsusunya koperasi syariah, karena mereka khawatir kalua syariah hanyalah atribut saja tanpa menerapkan nilai-nilai dan prinsip syariah yang sesungguhnya. Islamic Microfinance Institutions di Lamongan menjelma menjadi lembaga keuangan yang ada di hati Masyarakat Lamongan dengan memberikan nuansa Islami atau hablum minannas Islami yang selalu mengimbangi dengan prinsip Hablum minallah.

\section{WAKAF UANG}

Kata wakaf berasal dari bahasa yaitu waqafa, yaqifu waqfan yang berarti berhenti dan berdri. Sedangkan menurut wakaf menurut istilah adalah menahan harta yang mungkin diambil manfaatnya tanpa menghabiskan atau merusakkan bendanya dan digunakan untuk kebaikan. ${ }^{1}$ Sedangkan menurut terminologis, fiqih tampak diantara beberapa ahli, mereka berbeda pendapat atas definisi wakaf. Berikut beberapa ahli yang mendefinisikan tentang wakaf. ${ }^{2}$

Wakaf uang (cash waqf/waqf al-nuqud) adalah wakaf yang dilakukan oleh seseorang, kelompok orang, lembaga, atau badan hukum dalam bentuk uang. Dengan kata lain, wakaf uang merupakan perbuatan hukum wakif untuk memisahkan dana atau

${ }^{1}$ Adijani Al-Alabij, Perwakafan tanah di Indonesia dalam Teori dan Praktek (Jakarta: PT Raja Grafindo Persada, 2002), 25.

${ }^{2}$ Naziroeddin Rachmat, Harta Wakaf, Pengerptian dan Peprkembangan dan Sepjarpahnya di Dalam Masyarpakat Islam Dulu dan Sepkarang (Jakarta: Bulan Bintang, 1994), 22. 
menyerahkan sebagian harta benda miliknya yang berupa uang untuk dimanfaatkan selamanya atau untuk jangka waktu tertentu, sesuai dengan kepentingannya guna keperluan ibadah dana tau kesejahteraan umum menurut syariat Islam. ${ }^{3}$

Sejarah wakaf uang telah dipraktekkan sejak awal abad kedua Hijriah. Menurut Imam Az-Zuhri yang telah memfatwakan, bahwa mewakafkan dinar hukumnya boleh, dengan cara menjadikan dinar tersebut sebagai modal usaha dan keuntungannya yang disalurkan kepada orang yang membutuhkan. ${ }^{4}$

Selain Az-Zuhri, Ulama Madzhab Hanafi juga memperbolehkan wakaf uang dinar dan dirham sebagai pengecualian atas dasar Isthisnan bi al-'Urfi, yang merupakan apa yang dipandang oleh kaum muslim, dalam pandangan Allah SWT adalah baik, dana apa yang dipandang buruk olek kaum muslim dalam pandangan Allah SWT. juga buruk.

Berdasarkan pendapat para ulama diatas, pada taanggal 11 Mei 2002 MUI telah mengeluarkan fatwa tentang wakaf uang yang berisi: ${ }^{5}$ (1) Wakaf uang (cash waqf / waqf al-nuqud) adalah wakaf yang dilakukan oleh seseorang, kelompok orang, lembaga atau badan hukum dalam bentuk uang tunai. (2) Termasuk ke dalam pengertian uang adalah surat-surat berharga. (3) Wakaf uang hanya boleh disalurkan dan digunakan untuk hal- hal yang diperbolehkan menurut Syar'i. (4) Nilai pokok wakaf uang harus

${ }^{3}$ Muslim akuntansi, 394.

${ }^{4}$ Muslim akuntansi.

${ }^{5}$ MUI, Himpunan Fatwa Majlis Ulama Indonesia (Jakarta: MUI, 2011), 410. 
dijamin kelestariannya, tidak boleh dijual, dihibahka dan diwariskan. (5) Wakaf uang hukumnya jawaz (boleh).

Ada beberapa manfaat dari wakaf uang adalah: ${ }^{6}$

Seseorang memiliki dana terbatas sudah bisa mulai memberikan dana wakafnya tanpa harus menunggu menjadi tuan tanah terlebih dahulu. (2) Melalui wakaf uang, aset-aset wakaf yang berupa tanah-tanah kosong bisa mulai dimanfaatkan dengan pembangunan gedung atau diolah untuk lahan pertanian. (3) Dana wakaf uang juga bisa membantu sebagian lembaga-lembaga pendidikan Islam. (4) Umat Islam dapat lebih mandiri dalam mengembangkan dunia pendidikan tanpa harus terlalu bergantung pada anggaran pendidikan negara yang memang semakin lama semakin terbatas.

\section{DASAR HUKUM WAKAF}

Dasar hukum wakaf secara khusus tidak terdapat dalam AlQuran dan Hadits. Akan tetapi, makna dan kandungannya secara umum terdapat dalam dua sumber hukum islam tersebut. Ada beberapa ayat yang memberikan oerintah agar orang yang beriman bersedia untuk mendermakan hartanya demi kepentingan umum. Begitu juga dalam Hadits, ungkapan wakaf sering kita temui dengan ungkapan habs (tanah).7 Adapun dalil atau dasar hukum wakaf yang bersumber dari Al-Qur'an dan

\footnotetext{
${ }^{6}$ Rudy Haryanto, "Pengentasan Kemiskinan melalui Pendekatan Wakaf Tunai", dalam Al-Hikam Vol. 7 No. 1 Juni 2012, 192.

${ }^{7}$ Tim Penyusun Direktorat Pemberdayaan Wakaf, Pedoman Pengelolaan Dan Perkembangan Wakaf (Jakarta: Kementrian Agama RI, 2013), 25.
} 
Hadits, sebagaimana berikut: (1) Surat Al-Hajj ayat 77 yang berbunyi: "Hai orang-orang yang beriman, rukuklah kamu, sujudlah kamu, sembahlah Tuhanmu dan perbuatlah kebajikan, supaya kamu mendapat kemenangan. (2) Surat Al-Imran ayat 92 yang berbunyi: "Kamu sekali-kali tidak sampai kepada kebajikan (yang sempurna) sebelum kamu menafkahkan sebagian harta ang kamu cintai, dan apa saja yang kamu nafkahkan. Maka sesungguhnya Allah SWT. mengetahuinya. (3) Diriwayatkan dari Abu Hurairah r.a. bahwa Rasulullah saw bersabda: Apabila manusia wafat terputuslah semua amal perbuatannya, kecuali tiga hal, yaitu dari sedekah jariyah (wakaf), atau ilmu yang dimanfaatkan, atau anak shaleh yang mendoakannya. (HR. Muslim).

\section{RUKUN DAN SYARAT WAKAF}

Wakaf dikatakan sah jika rukun dan syarat wakat tekah terpenuhi. Oleh sebab itu, dalam pelaksanaannya harus diperhatikan rukun dan syaratnya. Adapun rukun-rukun wakaf, antara lain: ${ }^{8}$ (1) Orang yang berwakaf (wakif), (2) Harta yang di wakafkan (mauquf), (3) Tujuan wakaf (mauquf 'alaihii), (4) Pernyataan wakaf (sighat waqf).

Sementara itu, dalam undang-undang wakaf No. 41 pasal 6 tentang unsur wakaf, disebutkan bahwa wakaf dilaksanakan dengan memenuhi beberapa unsur wakaf, yaitu: (1) wakif, (2) 
nadzhir, (3) harga benda wakaf, (4) ikrar, (5) peruntukan harta benda wakaf, dan (6) jangka waktu wakaf. ${ }^{9}$

\section{SYARAT-SYARAT WAKAF}

Wakaf memiliki beberapa syarat, diantaranya adalah:10 (1) Tidak ada batasan waktu untuk melakukan wakaf. Sebab perbuatan wakaf berlaku untuk selamanya dan tidak untuk waktu tertentu. (1) Tujuan wakaf harus jelas. Seperti mewakafkan sebidang tanah untuk masjid, musholla, pesantren, makam, dan lain sebagainya. (2) Wakaf harus segera dilaksanakan setelah dinyatakan oleh orang yang mewakafkan, tanpa digantungkan pada peristiwa yang akan terjadi di masa yang akan datang. Sebab pernyataan wakaf berakibat lepasnya hak milik bagi yang mewakafkan, ini berkaitan dengan wasiat dan tidak berkaitan dengan wakaf. Dalam hal ini, berlakulah ketentuan-ketentuan yang berkaitan dengan wasiat. (4) Wakaf merupakan perkara yang wajib dilaksanakan tanpa adanya hak khiyar (membatalkan atau melangsungkan wakaf yang telah dinyatakan) sebab pernyataan wakaf berlaku dan untuk selamanya.

\section{MACAM-MACAM WAKAF}

Menurut ulama' secara umum, wakaf dapat dibagi menjadi dua bagian, yaitu :

9 Jaharuddin dan Bambang Sutrisno, Pengantar Ekonomi Islam (Jakarta: Salemba Diniyah, 2019), 197.

10 Jaharuddin dan sutrisno, 242. 
1. Wakaf Ahli (Khusus)

Wakaf ahli merupakan wakaf yang ditujukan kepada orang-orang teertentu, seorang atau lebih, baik keluarga wakif ataupun orpang lain. ${ }^{11}$ Misalnya, seseorang telah mewakafkan tanahnnya kepada anaknya, kemudian diturunkan lagi kepada cucunya. Maka, wakaf seperti ini dikatakan sah dan yang berhak menerima manfaatnya adalah orang yang telah ditunjuk dalam pernyataan wakaf tersebut. Wakaf ini biasany juga disebut dengan wakaf dhurri atau wakaf 'alal ulud, yang merupakan wakaf yang diperuntukkan bagi kepentingan dan jaminan sosial dalam lingkungan keluarga, lingkungan kerabat sendiri. ${ }^{12}$

Wakaf ahli ini dalam satu segi baik sepkali, karena wakif akan mendapatkan dua kebaikan, yaitu kebaikan dari segi amal ibadah wakafnya dan juga kebaikan dari sepgi silaturrahmi terhadap keluarga yang diberikan harta wakaf. Akan tetapi pada sisi lain, wakaf ahli ini sering menimbulkan beberapa masalah, seperti salah satu contoh jika anak cucu yang ditunjuk sudah tidak ada lagi siapakah yang berhak menerima manfaat harta wakaf itu? Atau bagaimana jika anak cucu wakif bertambah semakin banyak, sehingga menyulitkan untuk meratakan pembagian hasil harta wakaf $?^{13}$

Untuk mengantisipasi agar harta wakaf kelak tetap bisa dimanfaatkan dengna baik oleh anak cucunya dan berstatus hukum yang jelas, maka sebaiknya dalam ikrar wakaf, ahli waris

11Suhendi, Fiqih Muamalah, 244-245. 2006), 15.

${ }^{12}$ Direktorat Pemberdayaan Wakaf, Fiqih Wakaf (Jakarta: Kementrian Agama RI:

13Direktorat Pemberdayaan Wakaf, Fiqih Wakaf, 16. 
disebutkan bahwa wakaf ini untuk anak, cucu, kemudian kepada fakir miskin. Sehingga bila suatu ketika penerima wakaf tidak ada lagi, maka wakaf itu bisa langsung diberikan kepada fakir miskin. Akan tetapi, untuk kasus anak cucu yang menerima wakaf ternyat berkembang sedemikian banyak, kemungkinan akan menemukan kesulitan dalam pembagiannya secara adil dan merata.

\section{Wakaf Khairi (Umum)}

Wakaf khairi merupakan wakaf yang sejak semula ditujukan untuk kepentingan-kepentingan umum dan tidak ditujukan kepada orang-orang pilihan. Seperti keperluan untuk membangun masjid, madrasah, jempbatan, rumah sakit, panti asuhan dan lain sebagainya. ${ }^{14}$

Jenis wakaf ini jauh lebih bermanfaat dibandingkan dengan jenis wakaf $a h l i$, karena tidak memiliki batasan dalam hal kepemilikan. Dalam jenis wakaf ini juag, wakif dapat memanfaatkan harta yang telah diwakafkan, seperti mewakafkan tanahnya untuk dijadikan masjid, maka wakif boleh melaksanakan ibadah sholat disana Mewakafkan sumur, maka wakif boleh mengambil airnya sebagaimana yang pernah dilakukan oleh nabi SAW. dan sahabatnya Utsman bi Affan. ${ }^{15}$ Jika dilihat dari manfaatnya, wakaf ini bisa dirasakan untuk kepentingan kemanusiaan (umum) dan tidak hanya untuk keluarga wakif atau kerabatnya. 


\section{ERA SOCIETY 5.0}

Serpa mendefinisikan Society 5.0 adalah konsep yang diambil dari Orang Jepang yang bernama Harayama adalah masyarakat informasi yang dibangun di atas Society 4.0 yang bertujuan menciptakan masyarakat makmur yang berpusat pada manusia. Society 5.0 adalah konsep tehnologi yang berpusat pada manusia dan berkolaborasi dengan kecanggihan Tehnologi untuk menyelesaikan permasalahan sosial yang berintegrasi pada ruang dunia maya dan nyata.

Society 5.0 terbangun dari versi Society sebelumnya yaitu Society 1.0 (masyarakat berburu), Society 2.0 (masyarakat bertani), Society 3.0 (masyarakat industri), Society 4.0 (masyarakat informasi) dan kini Society 5.0 (masyarakat yang berintegrasi dengan sistem tehnologi IoT (Internet of Things) dan AI (Kecerdasan Buatan).

\section{ISLAMIC MICROFINANCE INSTITUTION}

Lembaga Keuangan Mikro Syariah atau Islamic Microfinance Institutions adalah Lembaga keuangan yang beroperasional dengan memperhatikan prinsip dan nilai-nilai ekonomi Islam. Salah satu nilai-nilai ekonomi Islam yang harus ada dalam lembaga keuangan syariah ini adalah amanah. Karena sebuah lembaga yang menerima amanah dari anggotanya atau nasabahnya untuk mengelola dan menyimpan dana (uang) yang dimilikinya agar bisa dijaga dan di manfaatkan dengan sebaik mungkin untuk kepentingan ummat. 
Lembaga keuangan syariah yang ruang lingkupnya mikro seperti Baitul Maal Wattamwil dan Koperasi Syariah merupakan lembaga keuangan yang ditumbuhkan dari peran masyarakat secara luas, tidak ada batasan ekonomi, sosial bahkan agama, semua komponen masyarakat dapat berperan aktif dalam membangun sebuah sistem keuangan yang lebih adil dan yang lebih pentinag mampu menjalankan lapisan pengusaha yang terkecil sekalipun. Dalam kegiatan keuangan syariah, seluruh transaksi yang terjadi harus dilaksanakan berdasarkan prinsipprinsip syariah. Prinsip syariah adalah prinsip hukum Islam dalam kegiatan perbankan dan keuangan berdasarkan fatwa yang dikeluarkan oleh lembaga yang memiliki kewenangan dalam penetapan fatwa di bidang syariah. Prinsip syariah yang dianut oleh lembaga keuangan syariah dilandasi oleh nilai-nilai keadilan, kemanfaatan, keseimbangan, dan universal.

Lembaga Keuangan Mikro Islam (islamic microfinance institution) adalah KSPPS BMT Mandiri Sejahtera Cabang Kranji memiliki kantor kas yang berada di Jl. Deandles Pasar Wage banjaranyar paciran lamongan. Kantor kas ini dulunya menjadi kantor cabang yang kemudian dijadikan sebagia kantor kas di BMT Kranji ini, dengna alasan karena minimnya minat nasabah yang nabung disana karena tempatnya yang kurang strategis. Kantor kas ini hanya ada satu karyawan yang ada disana, yaitu hanya seorang Teller.

Motto yang dimiliki oleh KSPPS BMT Mandiri Sejahtera Cabang Kranji adalah Mudah, Aman, dan Terhindar Dari Riba. 
Mudah yang berarti tidak mempersulit nasabah untuk melakukan penyimpanan ataupun pembiayaan. Kemudian Aman yang artinya memberikan kenyamanan semaksimal mungkin kepada nasabah, keamanan dalam penyimpanan barang atau uang yang ada di KSPPS BMT Mandiri Sejahtera. Dan yang terakhir adalah Terhindar Dari Riba yang merupakan pihak BMT Kranji tidak mengambil keuntungan yang terlalu banyak dan tidak seperti di bank konvesnional yang terkenal dengan sistem bunga. Sedangkan di KSPPS BMT Mandiri Sejahtera tidak menggunakan sistem bunga melainkan memberikan diskon atau hadiah kepada nasabah yang melakukan penyimpanan uang di koperasi tersebut

\section{PROFIL KSPPS BMT MANDIRI SEJAHTERA}

KSPPS BMT Mandiri Sejahtera Jawa Timur merupakan lembaga keuangan yang berbasis syariah yang berdiri pada tanggal 03 April 2005, sebelumnya lembaga ini belum berbasis syariah, kemudian mendapat badan hukum wilayah kabupaten Gresik dengan No. 03.BH.403.62/VI/2006 pada tanggal 13 Juni 2006. BMT ini berdiri dengan latar belakang masih banyak masyarakat sekitar yang melakukan praktik riba yang sangat merugikannya. Sehingga dengan adanya lembaga keuangan bisa membantu masyarakat dalam meminjamkan modal usaha kepada mereka. ${ }^{16}$

Lembaga keuangan ini berada di Jl. Raya Pasar Kliwon 01/01 Karangcangkring Dukun Gresik Jawa Timur dan sudah

16Khoirun Nisa', "Strategi Personal Selling Produk Tabungan Simaster (Simpanan Masyarakat Sejahtera) Pada BMT Mandiri Sejahtera Kantor Cabang Banjarwati Lamongan" Skripsi, Universitas Islam Negeri Maulana Malik Ibrahim Malang, 2018. 38-39. 
memiliki 26 cabang yang sudah tersebar di wilayah Gresik, Lamongan, Tuban. Salah satu cabang dari KSPPS BMT Mandiri Sejahtera Jawa Timur adalah KSPPS BMT Mandiri Sejahtera Cabang Kranji tepatnya di Jl. Raya Deandles Stand Pasar Kranji Paciran Lamongan dengan menggunakan prinsip syariah. KSPPS BMT Mandiri Sejahtera Cabang Kranji didirikan di pasar kranji karena memiliki tempat yang strategis dan banyak sekali yang melakukan transaksi yang diadakan di pasar atau di luar pasar. Bahkan hampir setiap hari ada orang yang mengajukan pembiayaan disana. KSPPS BMT Mandiri Sejahtera Cabang Kranji didirikan pada tanggal 13 Oktober 2013 yang merupakan cabang dari KSPPS BMT Mandiri Sejahtera Jawa Timur .

KSPPS BMT Mandiri Sejahtera Cabang Kranji memiliki kantor kas yang berada di Jl. Deandles Pasar Wage banjaranyar paciran lamongan. Kantor kas ini dulunya menjadi kantor cabang yang kemudian dijadikan sebagia kantor kas di BMT Kranji ini, dengna alasan karena minimnya minat nasabah yang nabung disana karena tempatnya yang kurang strategis. Kantor kas ini hanya ada satu karyawan yang ada disana, yaitu hanya seorang Teller.

JENIS - JENIS PRODUK KSPPS BMT MANDIRI SEJAHTERA CABANG KRANJI

Wadiah memiliki arti sebagai simpanan atau titipan yang harus dijaga dan dikembalikan kepada pemiliknya setiap saat 
sesuai dengan kehendaknya. ${ }^{17}$ Dalam KSPPS BMT Mandiri Sejahtera menawarkan tiga simpanan, diantaranya adalah : (1) Simaster (Simpanan Masyarakat Sejahtera), (2) Simpanan Haji dan Umroh, (3) Simpanan Qurban, (4) SIMJAKA (Simpanan Berjangka).

Selain simpanan, KSPPS BMT Mandiri Sejahtera Cabang Kranji juga terdapat beberapa produk pembiayaan, diantaranya : (1) Murabbahah, (2) Mudharabah, (3) Musyarakah, (4) Ijarah, (5) Hawalah, (6) Kafalah, (7) Qordul Hasan, (8) Rahn (gadai). Akad menggadaikan baranag dari satu pihak ke pihak yang lain, dengan uang sebagai barang gantinya. Pembiayaan rahn di BMT Mandiri sejahtera terdiri dari dua akad yakni akad qard dan akad ijarah yang bentuk pencairannya berupa uang tunai.

\section{ANALISIS IMPLEMENTASI WAKAF UANG DI KSPPS BMT MANDIRI SEJAHTERA CABANG KRANJI}

1. Proses Penyaluran Hasil Wakaf Uang

KSPPS BMT Mandiri Sejahtera Cabang Kranji memiliki tujuan pada salah satu produknya yaitu wakaf uang yang dijadikan sebagai produk unggulan dengan tujuan untuk mensejahterakan ekonomi umat, membantu fakir miskin, yatim piatu, dan kaum dhuafa. Dengan adanya wakaf uang di BMT ini, diharapkan mampu berperan dalam mengembangkan kegiatan-kegiatan sosial, ekonomi, maupun kesehatan.

Dalam voucher wakaf uang terdapat tulisan penggunakan hasil wakaf uang dan akan diberikan kepada: (1) Santunan anak yatim, piatu, dan fakir miskin. (2) Biaya pendidikan anak yatim 
piatu, dan fakir miskin. (3) Pendidikan, keagamaan, sosial dan kesehatan.

Berikut ini adalah gambar voucher wakaf uang yang dugunakan di KSPPS BMT Mandiri Sejahtera Jawa Timur.

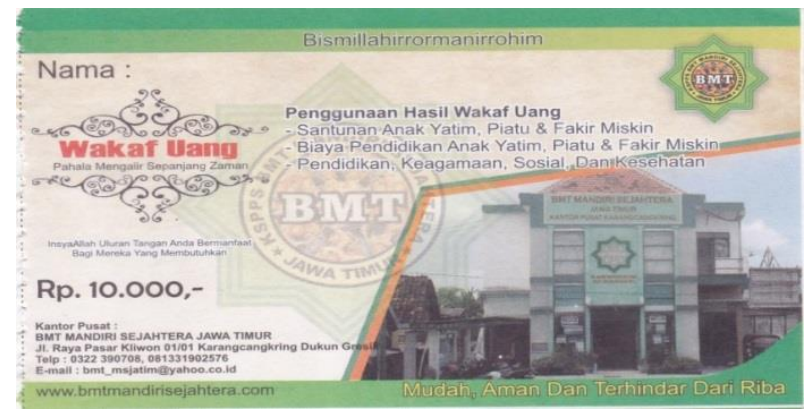

Gambar 3.2

Gambar voucher wakaf uang

Proses penyaluran wakaf uang dimulai dengan waqif menyerahkan uang kepada KSPPS BMT Mandiri Sejahtera Cabang Kranji melalui pembelian voucher wakaf uang atau pemontongan gaji bagi karyawan. Adapun yang menjadi penyalur dana dalam wakaf uang di KSPPS BMT Mandiri Sejahtera Cabang Kranji adalah: karyawan, anggota yang melakukan pembiayaan, anggota yang mendapatkan Sisa Hasil Usaha (SHU), peserta magang, PKL, Peneliti, dan masyarakat di sekitar kantor. Untuk mengelola dana wakaf uang, uang akan disetor ke kantor pusat setiap bulannya dan akan di salurkan kepada orang-orang yang membutuhkan. setiap orang yang melakukan pembiayaan, diwajibkan untuk membeli voucher wakaf uang sebanyak 1 lembar, dan mereka tidak bisa menolak dengan peraturan yang sudah ditetapkan oleh pengurus di KSPPS BMT Mandiri Sejahtera Cabang Kranji. 
Berikut ini hasil wawancara dengan salah satu karyawan yang ada di KSPPS BMT Mandiri Sejahtera Cabang Kranji. Untuk karyawan yang bekerja di BMT Mandiri Sejahtera, setiap bulannya akan dipotong gaji untuk membayar wakaf uang, ZIS dan simpanan khusus, sehingga karyawan yang ada disana setiap mendapatkan gaji tidak menerima gaji yang utuh. Pemotongan gaji untuk wakaf uang sebayar Rp. 10.000 per bulannya. Serta setiap kantor juga dijata untuk menjual wakaf uang tersebut. ${ }^{18}$

Selain wawancara dengan salah satu karyawan yang ada di KSPPS BMT Mandiri Sejahtera Cabang Kranji, penulis juga telah wawancara dengan salah satu anak magang yang ada disana: Untuk anak magang atau PKL harus menjual voucher wakaf uang 1 bandel (100 lembar) selama magang disana. ${ }^{19}$

Pengelolaan dana wakaf uang masih menjadi satu dengan pengelolaan dana ZIS yang ada di KSPPS BMT Mandiri Sejahtera Jawa Timur. Berikut data penerima santunan KSPPS BMT Mandiri Sejahtera Jawa Timur :

\begin{tabular}{|l|l|l|l|}
\hline Kantor & Anak & Ibu & Total \\
\hline Pusat & 9 & 12 & 21 \\
\hline Dukun & 27 & 8 & 35 \\
\hline Campurejo & 16 & 0 & 16 \\
\hline B. Panggang & 19 & 12 & 31 \\
\hline Sekapuk & 13 & 3 & 16 \\
\hline Sungelebak & 23 & 3 & 26 \\
\hline Tunjung mekar & 21 & 0 & 21 \\
\hline D. Sampeyan & 14 & 0 & 14 \\
\hline Moropelang & 37 & 0 & 37 \\
\hline Sembayat & 22 & 0 & 22 \\
\hline
\end{tabular}

${ }^{18 N a z i l a t u l ~ F a t i k h a h, ~ W a w a n c a r a, ~ S e l a k u ~ T e l l e r ~} 2$ di KSPPS BMT Mandiri Sejahtera Cabang Kranji, 22 Februari 2020.

${ }^{19}$ Friska Nur Auliyasari, Wawancara, Selaku Pelajar SMK NU Tracal, 19 Februari 2020. 


\begin{tabular}{|l|l|l|l|}
\hline Sidoharjo & 31 & 0 & 31 \\
\hline Benjeng & 19 & 3 & 22 \\
\hline Kranji & 31 & 2 & 33 \\
\hline Kedungpring & 45 & 0 & 45 \\
\hline Babat & 44 & 0 & 44 \\
\hline Kerek & 26 & 2 & 28 \\
\hline Sumberwudi & 25 & 0 & 25 \\
\hline Montong & 38 & 0 & 38 \\
\hline Merakurak & 27 & 2 & 29 \\
\hline Sukodadi & 18 & 0 & 18 \\
\hline Blimbing & 27 & 0 & 27 \\
\hline Sugio & 45 & 0 & 45 \\
\hline Pangean & 37 & 0 & 37 \\
\hline Sumberrejo & 18 & 0 & 18 \\
\hline Banjarawati & 9 & 1 & 10 \\
\hline JUMLAH & 641 & 48 & 689 \\
\hline
\end{tabular}

Tabel 3.2

Tabel penerima santunan di KSPPS BMT

Mandiri Sejahtera Cabang Kranji

\section{Motif Nasabah di KSPPS BMT Mandiri Sejahtera}

KSPPS BMT Mandiri Sejahtera Cabang Kranji terdapat beberapa motif nasabah yang ingin menjadi nasabah di BMT tersebut. Salah satunya adalah tempat yang strategis dan bisa terjangkau oleh berbagai nasabah di sekelilingnya, karena tempat KSPPS BMT Mandiri Sejahtera Cabang Kranji yang berada di pasar kranji. BMT ini telah memiliki kurang lebih 1000 nasabah yang telah menabung disana. Dalam hal ini, bisa menarik minat masyarakat untuk menabung di BMT ini, karena sudah ada bukti nasabah yang puas dengan pembiayaan yang ada di BMT.

Selain itu, ada beberapa nasabah yang motifnya terpaksa dengan peraturan yang mengikat. Maksud dari mengikat adalah nasabah yang melakukan pembiayaan diwajibkan untuk 
membayar wakaf uang. Salah satu alasannya adalah untuk syarat pengajuan pembiayaan agar dapat dicairkan oleh pihak KSPPS BMT Mandiri Sejahtera Jawa Timur. Selain orang yang melakukan pembiayaan, karyawan yang bekerja disana juga diwajibkan membayar wakaf uang perbulannya dengan memotong gajinya.

Sedangkan untuk anak PKL atau Magang yang ada disana, pihak BMT menyuruh menjual voucher wakaf uang kepada masyarakat. Seperti halnya yang dikatakan oleh saudara Siti Nur Azila yang sedang melakukan observasi disana, beliau berkata: "aku sodok kepekso ngedol wakaf uang iki nang bocah-bocah, mergo opo? Merane wakaf iku bersifat tabarru', la sedangkan nek aku gak ngedolno voucher iki, aku gak oleh magang nek kono". ${ }^{20}$

Maksud dari kata Siti Nur Azila tersebut adalah beliau terpaksa menjual voucher wakaf uang kepada orang-orang karena menjadi syarat untuk bisa magang di KSPPS BMT Mandiri Sejahtera. Hal ini terkesan sedikit memaksa, karena pada dasarnya wakaf uang merupakan salah satu amal jariyah yang bersifat tabarru' (saling tolong menolong).

Tetapi ada sebagian nasabah yang bermotif ikhlas untuk membeli wakaf uang tersebut. Seperti nasabah yang sedang menabung ke kantor dan kemudian mempunyai niatan untuk membeli voucher wakaf uang ini, dengan alasan agar beliau mendapatkan pahala dan bisa menolong orang yang membutuhkan dana tersebut. Contoh lain ketika anak magang menjual voucher wakaf uang yang kadang pembelinya ada yang terpaksa membeli karena kasihan dan ada pula yang ikhlas dengan 
adanya keterangan yang telah tetulis di voucher wakaf uang tersebut.

Oleh karena itu, dalam melakukan pengelolaan voucher wakaf ini terkesan memaksa waqif dan kebanyakan tanpa dorongan dari diri sendiri untuk membeli voucher tersebut, melainkan paksaan bahkan kewajiban untuk membayar wakaf uang demi mendapatkan apa yang diinginkan nasabah, seperti melakukan pembiayaan, magang, PKL, Observasi, dan penelitian.

\section{KESIMPULAN}

Proses penyaluran hasil wakaf uang di Islamic Microfinance Institution KSPPS BMT Mandiri Sejahtera di Era Society 5.0 ini dimulai dari waqif menyerahkan uang kepada KSPPS BMT Mandiri Sejahtera Cabang Kranji melalui pembelian voucher wakaf uang atau pemontongan gaji bagi karyawan. Adapun yang menjadi penyalur dana dalam wakaf uang di KSPPS BMT Mandiri Sejahtera Cabang Kranji adalah: karyawan, anggota yang melakukan pembiayaan, anggota yang mendapatkan Sisa Hasil Usaha (SHU), peserta magang, PKL, Peneliti, dan masyarakat di sekitar kantor. Untuk mengelola dana wakaf uang, uang akan disetor ke kantor pusat setiap bulannya dan akan di salurkan kepada orang-orang yang membutuhkan. setiap orang yang melakukan pembiayaan, diwajibkan untuk membeli voucher wakaf uang sebanyak 1 lembar, dan mereka tidak bisa menolak dengan peraturan yang sudah ditetapkan oleh pengurus di KSPPS BMT Mandiri Sejahtera. 
Motif nasabah di Islamic Microfinance Institution KSPPS BMT Mandiri Sejahtera di Era Society 5.0 memiliki beberapa motif, yaitu motif yang terpaksa dengan peraturan yang teriakat, seperti halnya nasabah yang melakukan pengajuan pembiayaan di KSPPS BMT Mandiri Sejahtera. Selain itu ada juga yang bersifat terpaksa, seperti anak magang atau PKL diwajibkan untuk menjualkan voucher wakaf uang sebanyak satu bendel selama magang disana. Oleh karena itu, dalam melakukan pengelolaan voucher wakaf ini terkesan memaksa waqif dan kebanyakan tanpa dorongan dari diri sendiri untuk membeli voucher tersebut, melainkan paksaan bahkan kewajiban untuk membayar wakaf uang demi mendapatkan apa yang diinginkan nasabah, seperti melakukan pembiayaan, magang, PKL, Observasi, dan penelitian.

\section{DAFTAR PUSTAKA}

Al-Alabij, Adijani. Perwakafan tanah di Indonesia Dalam Teori dan Praktek. Jakarta: PT Raja Grafindo Persada, 2002.

Karim, Adiwarman A. Ekonomi Makro Islam. Jakarta: Pt Raja Grafindo Persada, 2014.

A.Djazuli, A dan Yanwari, Yadi. Lembaga-Lembaga Perekoniman Umat Sebuah Pengenalan. Jakarta: Rajawali Press, 2002.

Direktorat Pemberdayaan Wakaf. Fiqih Wakaf. Jakarta: Kementrian Agama RI, 2006.

Hasan, Ahmad. Mata Uang Islami (Telaah Komprehensif Sistem Keuangan Islami), Terjemahan oleh Saifurrahman Barito, Zulfikar Ali, Edisi 1. Jakarta: RajaGrafindo Persada, 2005.

Haryanto, Rudy. "Pengentasan Kemiskinan melalui Pendekatan Wakaf Tunai”, Al-Hikam Vol. 7 No. 1 Juni 2012.

Hutabarat, Delina. Pelajaran Ekonomi SMU II. Jakarta: Erlangga, 1997.

Swardono. Uang dan Bank. Yogyakarta: BPFE Universitas Gajah Mada, 2010. 
Jaharuddin dan Sutrisno, Bambang. Pengantar Ekonomi Islam. Jakarta: Salemba Diniyah, 2019.

Khoirun Nisa'. 'Strategi Personal Selling Produk Tabungan Simaster (Simpanan Masyarakat Sejahtera) Pada BMT Mandiri Sejahtera Kantor Cabang Banjarwati Lamongan Malang". Skripsi, Universitas Islam Negeri Maulana Malik Ibrahim Malang, 2018.

MUI. "Himpunan Fatwa Majlis Ulama Indonesia". Jakarta: Sekretaris MUI, 2011.

Riza Salman, Kautsar. Akuntansi Perbankan Syariah Berbasis PSAK Syariah. Jakarta:Permata Puri Media, 2012.

Sudarsono, Heri. Bank dan Lembaga Keuangan Syariah. Yogyakarta: Ekonosia, 2007.

Suhendi, Hendi. Fiqih Muamalah. Jakarta: PT Rajagrafindo Persada, 2016.

Tim Penyusun Direktorat Pemberdayaan Wakaf. Pedoman Pengelolaan dan Perkembangan Wakaf . Jakarta: Kementrian Agama RI, 2013.

Rachmat, Naziroeddin. Harta Wakaf, Pengertian dan Peprkembangan dan Sejarahnya didalam Masyarakat Islam Dulu dan Sepkarang. Jakarta: Bulan Bintang, 1994. 